\title{
OS PRINCIIPIOS GERAIS DO DIREITO CIVIL
}

\author{
Carmem Lucia Silveira Ramos \\ Direito - texto para \\ a disciplina de Filosofia do Direito.
}

SUMĀRIO: 1. A visão tradicional dos princípios gerais do direito. 2. Princípios gerais e valores jurídicos. 3. Os princípios gerais do direito civil. 4. Princípios gerais e transformação social. 5. Princípios gerais e legitimação ideológica.

\section{A VISÃO TRADICIONAL DOS PRINCIPIOS GERAIS DO DIREITO}

A partir de sua tradição racionalista, o direito tem pautado seus ditames, fundamentalmente, na preocupação com a sistematização, com a organização da ordem jurídica. Conseqüência disto é atribuir-se menor relevo à adequação do direito à realidade social, ou seja: a preocupação maior deixa de ser o aperfeiçoamento da sociedade, como tal, transformando-se no objetivo de melhoria do sistema jurídico.

Se a noção de sistema, neste passo, justifica o fato de as posições doutrinárias carentes de significação para os problemas humanos se multiplicarem, também a partir da idéia de sistema se pode chegar aos princípios gerais do direito. Isto porque tais princípios não são senão normas fundamentais do sistema, as normas mais gerais que existem. (cf. NORBERTO BOBBIO, Teoria dell'ordinamento giuridico, Torino, G. Piappichelli Editore, 1960, p. 181). Como tal, os ordenamentos jurídicos via de regra consagram que, inexistente texto expresso para a solução de um determinado caso concreto, deve-se recorrer aos princípios gerais do direito. São exemplos disso o artigo 40. da Lei de Introdução ao Código Civil Brasileiro e o artigo 10. do Código Civil Espanhol.

O tema dos princípios gerais do direito se relaciona, pois, paralelamente ao problema da completude ou não do ordenamento jurídico, à questão das lacunas da lei, ou do direito e às diretrizes da hermenêutica jurídica.

Não há como ignorar, preliminarmente, sobre a questão, a impossibilidade de 0 juiz, face à demanda que lhe é proposta, deixar de proferir uma decisão, o que implicaria no "déni de justice" da lei francesa, 
aliada à circunstância, hoje geralmente aceita, de que as necessidades sociais são tão variadas, as relações humanas tão ativas, os interesses tão diversos e seus efeitos tão extensos, que se torna praticamente impossível ao legislador formular uma previsão de tudo, de onde a admissão da existência de lacunas no ordenamento jurídico positivo ser quase pacífica. (cf. PAUL FORIERS et NORBERTO BOBBIO, in Le problème des lacunes en Droit, Ėtudes publiées par $\mathrm{CH}$. PERELMAN, Bruxelles, Établissements Émile Beyland, Société Anonyme d'Éditions Juridiques et Scientifiques, 1968, p. 13), a despeito da posição em contrário, que pode ser apontada como típica exceção, sustentada, v. g., por KELSEN.

Mesmo aqueles que adotam posição doutrinária "dogmática" ou "normativista", se encontram respaldo para suas teses no âmbito, por exemplo, do direito penal, em que a incidência específica no tipo previsto em lei é imprescindível para a imposição da sanção, no campo do direito civil costumam aceitar e não se furtam mesmo à invocação, para a solução do caso concreto, de lições da doutrina, de entendimento jurisprudencial, dos costumes e até mesmo de aplicação da analogia, da equidade e dos princípios gerais do direito, ou seja, admitem a presença de claros no conjunto de normas colocadas à sua disposição e, por via de conseqüência, à disposição do juiz em face de uma determinada demanda que Ihe é apresentada, pedindo solução, de onde a utilização de tais recursos, ante o silêncio da lei.

Tendo em vista este dado real e legal, um outro problema logo se impõe: a noção de princípios gerais de direito não é unívoca. Isto tem incontestável relevância não apenas no plano teórico, mas precipuamente conseqüências no âmbito de sua aplicação prática, pois, como asseverou R. LIMONGI FRANÇA, a "simples referência a esses princípios, tal como se encontra na lei, não resolve para o intérprete e aplicador do Direito, o problema prático de sua adequação aos casos concretos, para cujo destrinçamento não seja possível invocar algum texto de lei ou alguma regra consuetudinária." (in Princípios gerais do direito, São Paulo, Ed. Revista dos Tribunais Ltda., 1971, p. 14).

Dentre as diversas correntes em torno da conceituação dos princípios gerais do direito, encontramos autores que os elevam à condição de princípios do direito natural (como DEL VECCHIO e RECASÉNS SICHES); outros que os resumem na equidade (conforme MAGGIORE e SCIALOJA) e ainda autores para quem os princípios gerais do direito constituem-se em regras gerais, introduzidas nos sistemas jurídicos seja pela filosofia do direito, seja pela ciência do direito, mas sempre com caráter de universalidade (como PACCHIONI e CLÓVIS BEVILÁQUA).

Ademais, tem-se afirmado serem os princípios gerais do direito os critérios básicos de fundamentação de um sistema jurídico (COVIELLO), ou os valores básicos para a preservação da ordem social, havendo ainda os que adotam posição positivista, vendo os princípios gerais do direito como extraídos do próprio sistema jurídico (como CARNELUTTI e RUGGIERO) e os que adotam posição eclética, pro- 
curando, por exemplo, conciliar os princípios sistemáticos com as normas do direito natural.

Isto posto, numa conclusão preliminar, é possível afirmar que estes princípios têm sido tratados, sempre, como voltados para o direito em si e não para a realidade social cambiante, independente da diversidade de noções que têm merecido; em face dos diferentes posicionamentos filosóficos dos autores que abordaram a matéria.

\section{PRINCIPIOS GERAIS E VALORES JURIDICOS}

Para alguns autores, dentre eles NORBERTO BOBBIO, os princípios gerais do direito são normas, como qualquer outra (ob. cit., p. 181)

Assim, por exemplo, no Código Civil Italiano, a regra do artigo 2.043, que trata do ressarcimento por fato ilícito seria, simplesmente, a consagração de um dos princípios fundamentais da convivência social: o "neminem laedere"; o artigo 2.041, o repúdio do enriquecimento sem causa; o artigo 1.176, ao dispor sobre o cumprimento das obrigações, importaria na tradução legal do princípio" pacta sunta servanta". Tais normas, no dizer de CRISAFULLI, citado por BOBBIO, seriam princípios gerais do direito expressos.

A par destes, existiriam os princípios não expressos, hipóteses que se enquadrariam na norma do artigo 12 das "disposições sobre a lei em geral" do Código Civil Italiano, dispositivo que, em termos gerais, considera a existência de lacunas na lei e estabelece os meios pelos quais devem ser completadas, para tanto prevendo, em última instância, a invocação dos princípios gerais do ordenamento jurídico do Estado, ou seja, dos valores básicos consagrados pela legislação italiana, a serem adotados na hipótese de inexistência de disposição precisa ou análoga a regular um caso concreto.

Para que se possa explicitar estes valores, é mister verificar, dentre as normas contidas na Constituição da República da Itália, quais os princípios que se pode extrair, verificando-se, a partir de análise sumária de seu texto, que poderiam ser resumidos aos direitos fundamentais do homem, a saber: os direitos de personalidade (art. 2?); os direitos de cidadania (art. 30.); o direito e a proteção ao trabalho (arts. 40., 35 e 36); a proteção à família (art. 29); a liberdade de iniciativa econômica (art. 41); a proteção à propriedade (art. 48) e o direito à livre iniciativa (art. 45).

Tais princípios, portanto, encontram-se consagrados na legislação italiana atual, de sorte a estarem protegidos não apenas em normas expressas e específicas da legislação ordinária, mas também acima delas, no texto constitucional, de vez que envolvem os valores jurídicos básicos daquele país, em consonância com o sistema sócio-político-econômico ali vigente.

Importam, assim, em princípios gerais do direito que não podem ser pura e simplesmente extraídos das normas jurídicas.

Preocupada com a existência destes princípios gerais do direito 
não expressos em regras específicas, assevera MARIA HELENA DINIZ: “Os princípios gerais do direito, portanto, em sua grande maioria, não estão declarados nas normas jurídicas, porém nelas estão implícitos, podendo ser descobertos, mediante a análise dos subsistemas componentes do sistema jurídico, relativos ao tema controvertido que se quer decidir." (in As lacunas no direito, São Paulo, Ed. Revista dos Tribunais, 1981, p. 193).

O que se pode inferir desta citação, sobretudo e ainda uma vez, é a sempre presente preocupação com o sistema, com a racionalização na consideração do tema dos princípios gerais do direito, ainda que a autora conteste sejam eles normas formuladas objetivamente com valor de generalidade (ob. cit., p. 198), contrariamente ao que sustentam autores como NICOLAU NAZO e BOBBIO.

CARLOS MAXIMILIANO, também preocupado com a noção de sistema, vê os princípios gerais do direito como "as diretivas idéias do hermeneuta, os pressupostos científicos da ordem jurídica" (cf. Hermenêutica e aplicação do direito, Rio de Janeiro, Forense, 1979, p. 295) de sorte que, na hipótese de existir lacuna na lei não suscetível de ser preenchida de outro modo, compete ao intérprete inovar, indutivamente, o trabalho do legislador, subindo, em processo de generalização sucessiva, até encontrar a solução colimada nos "altos ditames" do ordenamento jurídico. (ob. cit., p. 295/6).

Relativamente à aplicação deste processo de indução para extrair os princípios gerais do direito parece haver certa concordância entre os autores (cf. MARIA HELENA DINIZ, ob. cit., p. 201/2); este ponto de vista, no entanto e indubitavelmente, prende-se à idéia de vinculação das normas jurídicas a uma diretriz maior, a qual deve ser buscada até atingir o princípio a prevalecer para a solução do caso concreto, vale dizer, pressupõe a idéia de sistema.

Diante disto, aplicar os princípios gerais do direito seria compreender os valores em que se inspirou a ordem jurídica positiva, adotando-os no caso concreto, pois estes princípios seriam, nada mais, nada menos, do que a tradução destes valores consagrados pelo sistema jurídico, em face de uma determinada ordem sócio-político-econômica, de um determinado período histórico.

De outra parte, uma vez que já foram apontados alguns dados e discrepâncias doutrinárias relativamente ao que vêm a ser os princípios gerais do direito, mister se faz, dentro deste enfoque tradicional do problema, ingressar no labirinto jurídico até atingir os valores básicos que, via de regra, se erigem em princípios, eis que se pretende explicitar pelo menos alguns deles.

A questão de quais seriam, especificamente considerados, os princípios gerais do direito, vem preocupando os autores desde Roma, onde já houve a preocupação de ordená-los em coletâneas de máximas jurídicas na tentativa de, se não sistematizá-los, pelo menos enumerá-los exaustivamente. 
Neste passo, a capacidade de agir, como princípio de direito material e processual, a liberdade de forma dos atos e negócios jurídicos, o dever de cumprimento da obrigação assumida (pacta sunt servanda), a responsabilidade civil pelo prejuízo experimentado por outrem (altere non laedere), a tutela da boa fé, a obrigação de fazer ou não fazer exigível apenas a partir de dispositivo legal, seriam alguns deles.

A título exemplificativo, WASHINGTON DE BARROS MONTEIRO indica, como princípios gerais do direito: “a) ninguém pode transferir mais direitos do que tem; b) ninguém deve ser condenado sem ser ouvido; c) ninguém pode invocar a própria malícia; d) quem exercita o próprio direito não prejudica a ninguém; e) pacta sunt servanda; f) quod initio vitiosum est non potest tractu temporis convalescere." (in Curso de Direito Civil, vol. I, São Paulo, Ed. Saraiva, 1975, p. 42).

Dentro do sistema sócio-político-econômico em que se encontram inseridos, traduzem estes princípios os valores básicos do liberalismo: princípio da ampla defesa, liberdade de contratar, garantia dos direitos subjetivos reconhecidos pelo sistema.

Poder-se-ia ainda enumerar, sempre sem a pretensão de exaurir o tema: o princípio da oralidade e da publicidade no processo; o princípio da auto-determinação dos povos; a proteção da dignidade humana; o 'locus regit actum'; 'prior in tempore potior in iure'; 'res perit domino'; 'non bis in idem'; 'suum cuique tribuere'; a igualdade e até a controvertida justiça.

Esta enumeração exemplificativa dos princípios gerais do direito, por si só, é suficiente para corroborar a assertiva inicial de que envolvem eles, nada mais, nada menos, do que a consagração dos valores fundamentais da ordem jurídica, do 'status quo' vigente, cuja mantença seu objetivo é garantir, em nome do sistema, afastadas quaisquer considerações em torno da realidade e necessidades sociais do momento.

\section{OS PRINCIPIOS GERAIS DO DIREITO CIVIL}

Numa tentativa de explicitar os princípios gerais do direito civil, sem pretender esgotar a matéria, mas a partir da preocupação básica de fixar, dentre os princípios apontados, aqueles valores consagrados e que se encontram subjacentes aos mesmos, cumpre referir, relativamente à relação de fundamentação dos conteúdos dos princípios especificamente compreendidos no contexto do direito civil, conforme o posicionamento tradicional relativo ao tema, o seguinte:

$\mathrm{Na}$ enumeração de MARIA HELENA DINIZ (ob. cit., p. 193/4), alguns dos princípios contidos naquele que denomina "sistema jur ídico civil" poderiam ser assim enunciados (de vez que também não pretendeu a autora formular uma relação totalmente abrangente, o que, 'digase de passagem, seria bastante difícil): "o da moralidade, que impõe deveres positivos na obrigação de agir e negativos na abstenção de certos atos contrários aos sentimentos coletivos; b) o da igualdade de direitos e deveres frente ao ordenamento jurídico; c) o da proibição de locuple- 
tamento ilícito; d) o da função social da propriedade; e) o de que ninguém pode transferir ou transmitir mais direitos do que tem; f) o de que a boa fé se presume, a má fé deve ser provada; g) o da preservação da autonomia da instituição familiar; $h$ ) o de que ninguém pode invocar a própria malícia; i) o da exigência da justa causa nos negócios jurídicos; j) o de que o dano causado por dolo ou culpa deve ser reparado; k) o de que as obrigações contraídas devem ser cumpridas (pacta sunt servanda); I) o dos pressupostos da responsabilidade civil; $m$ ) o de que quem exercita o próprio direito não prejudica ninguém; n) o do equilíbrio dos contratos, que condena todas as formas de onerosidade excessiva para um dos contratantes; o) o da autonomia da vontade e da liberdade de contratar; p) o da intangibilidade dos valores da pessoa humana ou do devido respeito à personalidade humana; q) o de que a interpretação a ser seguida é aquela que se revelar menos onerosa para o devedor; r) o de que quando for duvidosa a cláusula do contrato, deve-se conduzir a interpretação visando aquele que se obriga; s) o de que se responde pelos próprios atos e não pelos dos outros; $t$ ) o de que se deve favorecer mais aquele que procura evitar um dano, do que aquele que busca realizar um ganho; $u$ ) o de que não se pode responsabilizar alguém mais de uma vez pelo mesmo fato; v) o de que nas relações sociais se tutela a boa fé e se reprime a má fé, etc. ..."

Esta enumeração, por abranger os princípios gerais do direito civil relacionados por vários outros autores, dentre os quais MIGUEL REALE, WASHINGTON DE BARROS MONTEIRO e MESSINEO, pela sua maior amplitude é adotada como básica para ratificar a assertiva de que, ainda para aqueles que vêm tais princípios como autênticas normas legais, componentes do sistema jurídico positivo e não como preceitos de ordem sociológica, ética ou política, não há como se contestar traduzam os princípios gerais do direito, pura e simplesmente, os valores consagrados pelo sistema sócio-político-econômico através do texto legal editado, sendo, portanto, autêntica expressão dos valores da sociedade liberal neo-capitalista, que se pretende preservar, tais como a isonomia (muito embura formal), a autonomia da vontade (ainda que uma ficção, ante as pressões sofridas pelo economicamente mais fraco), a função social da propriedade (conquista neo-liberal, mas que, em verdade, só prevalece na medida em que não ofenda aos interesses da classe dominante) e assim por diante.

Por todo o exposto, obvia-se que, envolvam os princípios gerais do direito, ou os princípios gerais do direito civil especificamente, pensamentos de natureza normativa ou enunciativa (como o princípio de que a boa fé se presume, ou o do equilíbrio dos contratos), ou verdadeiros princípios materiais (como o 'alterum non laedere'), sejam mais ou menos amplos, por um lado; por outro, mesmo não havendo uma relação completa de princípios gerais do direito, de onde a eventual dificuldade de qualificação de uma ou outra hipótese como tal, o que não há como se ilidir é que, ainda que não homogêneos, ainda que algumas vezes seja controvertido e difícil seu enquadramento ou classi- 
ficação, estão eles, por assim dizer, sempre a serviço do sistema vigente, traduzindo o "critério básico de fundamentação de um sistema jurídi$\infty^{\prime \prime}$ na assertiva de CARLOS ENRIQUE PETTORUTI, e, obrigatoriamente, por este motivo, espelhando a ideologia dominante, que os detentores do poder pretendem manter a qualquer custo.

\section{PRINCIIPIOS GERAIS E TRANSFORMAC̣ĀO SOCIAL}

O processo de racionalização do direito, que se desenvolveu durante séculos, a partir do feudalismo, passando pelos Estados modernos centralizados, com suas monarquias absolutas e principados dotados de exércitos próprios, até chegar, finalmente, a dominar com o racionalismo do século XVIII, erigido à condição de sistema e em função da Revolução Francesa e da sociedade industrial, foi certamente favorecido por fatores políticos e econômicos.

É inconteste que os sistemas de direito, como os temos hoje, são fruto de uma reorganização do poder político, centrada contra os privilégios da aristocracia absolutista. Simultaneamente, porém, este processo de racionalização, que corresponde aos sistemas jurídicos da atualidade, trouxe consigo características correspondentes aos interesses econômicos da burguesia, no exercício de suas atividades financeiras, comerciais e industriais, e em detrimento das classes economicamente mais fracas.

Este pensamento passou a ser a base da ideologia jurídica, estrutura em função da qual se organizam os conteúdos das normas de direito.

Desta sorte, a racionalização do direito indubitavelmente foi um dos aspectos que acabou por torná-lo algo estático: os juristas, investidos em funções políticas, administrativas e judiciárias, contribuiram para a formação do Estado moderno, burocrático e centralizado, mas sempre agiram atendendo aos interesses dos detentores do poder econômico, do comércio e da indústria, vale dizer, do capitalismo, tendo em vista sua própria formação social e filosófica.

Conforme a assertiva de PHILIPPE GÉRARD: “. . . la conception du droit comme système cohérent de dispositions générales et abstraites régissant l'activité des individus nous semble procéder de deux sources principales. D'une part, elle résulte de la mise en oeuvre d'un processus symbolique qui, dès l'époque moderne, structure les légitimations idéologiques du droit. D'autre part, elle est issue d'une tendance à la rationalisation formelle dont les origines historiques résident dans les impératifs inhérents à l'extension progressive du mode de production capitaliste". (in Droit, égalité et idéologie, Bruxelles, Publications des Facultés Universitaires Saint - Louis, 1981, p. 381).

$O$ pensamento jurídico tem, portanto e tradicionalmente, dentro de si aquilo que LUIZ FERNANDO COELHO denominou de "idealismo ontológico", o qual, a partir da idéia do primado da lei, levou o ju- 
rista ao dogmatismo e a encarar o direito cada vez mais como princípios gerais (cf. Introdução à crítica do direito, Curitiba, HDV, 1983, p. 38), eis que através destes princípios gerais se passou a traduzir a ideologia dominante.

Daí a afirmação de que os princípios gerais do direito são encarados como voltados para o direito em si e não para a realidade social.

Por outro lado, na medida em que se pretenda ver o direito como algo prospectivo, como o faz a teoria crítica do direito na formulação de LUIZ FERNANDO COELHO, isto é, como o presente que constrói para o futuro, inarredável se revela a incompatibilidade dos princípios gerais do direito, categoria tradicionalmente consagrada, com uma perspectiva crítica.

Para que se chegue ao enfoque crítico, contudo, mister se faz que se passe a entender o sistema legal como uma ordem real, em face de uma estrutura de poder político e em constante transformação, e não uma ordem lógica, conservadora, conforme tradicionalmente se concebe a partir do racionalismo oitocentista.

A partir daí, o sistema passa a ser interpretado "como interdisciplinariedade, envolvendo o continente histórico a que alude Althusser, o que exige conhecimentos básicos de sociologia, economia, política e filosofia." (cf. LUIZ FERNANDO COELHO, Lógica jurídica e interpretação das leis, Rio de Janeiro, Forense, 1981, p. 216).

Esta noção preliminar, ainda segundo LUIZ FERNANDO COELHO, torna-se imprescind ível para que se possa pensar o direito em função da dialeticidade do social. (cf. Introdução à crítica do direito, p.18) Outrossim, este enfoque choca-se frontalmente com a idéia de princípios gerais do direito, na medida em que, traduzindo estes a ideologia dominante no sistema jurídico, importam no enquadramento do homem, do ponto de vista jurídico, aos ditames dominantes da sociedade numa determinada época de sua evolução, de sorte a tentar preservar a ordem social como ela é, manter o 'status quo' vigente e não visar sua transformação e aperfeiçoamento, consoante seria desejável.

Isto porque, conforme já visto, os princípios gerais do direito derivam-se de dois postulados básicos: (a) o primeiro deles, de natureza racional e formal, implica na idéia tradicional de sistema, ou seja, na noção de que a ordem jurídica positiva constitui-se em um todo coerente e completo de disposições, do qual sempre se pode extrair a solução de um litígio, excluindo-se desta sorte a idéia de sistema como interdisciplinariedade, conforme sustenta a teoria crítica do direito; (b) o segundo, o postulado de que a lei deve promover uma adequada regulamentação de todos os fatos sociais (vinculado, pois, à lógica material), se traduz, nos princípios gerais do direito, como observância e respeito aos valores tidos como essenciais e que objetivam a garantia de coerência da ordem jurídica, traduzindo, portanto, a ideologia dominante, e afastando a idéia do homem como único e exclusivo destinatário da estrutura social. 


\section{PRINCIPIOS GERAIS E LEGITIMAÇĀO IDEOLOGICA}

Corroborando a argumentação básica antes desenvolvida, isto é, apontados os princípios gerais do direito civil como formas de legitimação ideológica de um sistema de dominação, cujo objetivo maior é dissimulá-lo, cabe lembrar, quanto a alguns dos princípios gerais do direito civil:

(a) o denominado "princípio da moralidade", que obriga a agir ou abster-se de atos em respeito à coletividade, obviamente nada mais é do que a tradução do valor consubstanciado no respeito ao direito positivo em vigor (o primado da lei), desta sorte implicando na observância dos valores básicos do sistema vigente, qual seja, no respeito à ordem de valores tidos como fundamentais pelos detentores do poder e que, com isto, são transmitidos como supostamente consagrados pela consciência popular;

(b) o princípio da isonomia (que envolve, de fato, mera igualdade formal entre os homens), da função social da propriedade (interpretada, como tal, dentro da estrutura vigente), a autonomia da vontade (ficção que ignora as pressões econômicas sofridas pelos menos favorecidos), a liberdade de contratar, "o pacta sunt servanda" e os próprios direitos fundamentais do homem são interpretados segundo o enfoque dos valores básicos e fundamentais do sistema liberal, burguês, hoje na sua versão neo-capitalista;

(c) a consagração da boa fé e a consequente observância do princípio da segurança jurídica trabalha, incontestavelmente, em favor da manutenção do sistema sócio-político-econômico, que se pretende a todo custo conservar;

(d) do mesmo modo, a preservação e autonomia da instituição familiar, tendo como núcleo básico o casamento, não significa outra coisa senão sustentar o valor-máter do sistema social, que a estrutura política tudo faz para preservar e manter, à pena de alteração de todo o quadro da realidade social contemporânea;

(e) ademais, o princípio da responsabilidade civil, consagrado na máxima latina "alterum non laedere", presta-se também à mantença dos valores do sistema, na medida em que a obrigação de indenizar só surge quando existe proteção legal em favor do prejudicado, qual seja, a partir da ofensa a bens e valores protegidos pela ordem jurídica.

$\mathrm{O}$ que se pretende demonstrar, nesta série de exemplos e em consonância com o raciocínio já anteriormente desenvolvido é que, indicado qualquer princípio geral do direito, ou, especificamente, do direito civil, se encontrará sempre, oculto atrás do princípio, bens, valor ou valores que se pretende legitimar e preservar, visando a estratificação, a manutenção das condições da sociedade como ela é, muito lenta e gradativa se mostrando a evolução destes valores, a pretexto de uma suposta segurança e estabilidade sociais, o que, na realidade, vem a se configurar num sistema de dominação.

Os princípios gerais do direito surgem, portanto, em função de 
uma idealização do ordenamento jurídico, e a partir de noções abstratas como a que vê no homem o sujeito do direito, ou a concepção da igualdade como equivalência de prerrogativas individuais, ou ainda a concepção do Estado e da norma jurídica como garantidores da liberdade, e assim por diante.

Desta sorte, inafastável é que, como asseverou PHILIPPE GÉRARD, "Les valeurs et représentations qui justifient les principes généraux peuvent, en effet, se prêter à une critique partant sur l'idéologie juridique (ob. cit., p. 16). E adiante: "Contredites par certaines dispositions positives, démenties par les rapports sociaux visés par les dispositins qu'elles justifient, les valeurs et représentations qui sous-tendent les principes généraux présentent une conception déformée de la cohésion sociale. Mais, par le biais de cette reconstitution fallacieuse, les valeurs et représentations contribuent à préserver les rapports issus de la divison sociale, grâce à la médiation du droit positif et, en l'espèce, des principes généraux non écrits." (ob. cit., p. 16).

Uma análise crítica da aplicação dos princípios gerais do direito demonstra, desta sorte e à evidência, sua natureza ideológica. Correspondem eles a uma representação imaginária dos valores da sociedade capitalista que se pretende preservar, que se quer permaneça como está, sem examinar se estes fatos econômicos, políticos e sociais que os princípios preservam correspondem efetivamente aos anseios da coletividade, ou se fatalmente seriam elididos na medida em que se afastasse esta representação ideológica que justifica certas disposições jurídicas e os próprios princípios gerais do direito.

O quadro social e jurídico originado da ascensão da burguesia foi igualitário, mas apenas na sua forma, pois simultaneamente desenvolveram-se e generalizaram-se dispositivos voltados para a proteção do poder econômico, das classes dominantes e regras disciplinares (v. g. normas de direito penal) que no seu conteúdo e aplicação revelaram-se essencialmente desiguais e assimétricas. Assim sendo, como observou MiCHEL FOUCAULT, o contra-direito se tornou o conteúdo efetivo e institucionalizado das formas jurídicas.

$\mathrm{Na}$ expressão de FOUCAULT: "A modalidade panóptica do poder - ao nível elementar, técnico, humildemente físico em que se situa - não está na dependência imediata nem no prolongamento direto das grandes estruturas jurídico-políticas de uma sociedade; ela não é entretanto absolutamente independente." (in Vigiar e punir, Petrópolis, Editora Vozes Ltda., 1977, p. 194). E adiante, explicando o regime político que passou a ter na burguesia a classe dominante: A forma jurídica geral que garantia um sistema de direitos em princípio igualitários era sustentada por esses mecanismos miúdos, cotidianos e físicos, por todos esses sistemas de micropoder essencialmente inigualitários e assimétricos que constituem as disciplinas. E se, de uma maneira formal, o regime representativo permite que direta ou indiretamente, com ou sem revezamento, a vontade de todos forme a instância fundamental 
da soberania, as disciplinas dão, na base, garantia da submissão das forcas e dos corpos. As disciplinas reais e corporais constituiram o subsolo das liberdades formais e jurídicas. $O$ contrato podia muito bem ser imaginado 'como fundamento ideal do direito e do poder político; o panoptismo constituía o processo técnico, universalmente difundido, da coerção. Não parou de elaborar em profundidade as estruturas jurídicas da sociedade, para fazer funcionar os mecanismos efetivos do poder ao encontro dos quadros formais de que este dispunha. As "Luzes" que descobriram as liberdades inventaram também as disciplinas." (ob. cit., p. 194/5).

Neste passo o sistema, formado como nação, destruiu e massacrou as minorias, como os índios, e até a maioria dos economicamente mais fracos, tudo em nome dos interesses da burguesia dominante.

Ao mesmo tempo, a irreal e fictícia análise dos fatos jurídicos (encarados a partir da natureza jurídica dos institutos em que se enquadram os fatos sociais de que se originam), traduzindo a mentalidade da onipotência da lei, impede ou pretende impedir o jurista de questionar em torno da efetiva realidade sócio-político-econômica e de quais seriam os rumos para esta sociedade, qual o sentido de futuridade a buscar na aplicação do direito, ou através dele.

Como disse LUIZ ALBERTO WARAT: “EI mito puede así llevarnos a un ocultamiento de la realidad coexistencial". (in Abuso del derecho y lagunas de la ley, Buenos Aires, Abeledo Perrot, 1969, p. 95).

Esta atitude de fuga da realidade, no entanto, é justificável, com uma característica do ser humano: a de procurar eximir-se de responsabilidade, como bem observou ALF ROSS: “los seres humanos, para escapar a la responsabilidad de la decisión y a la agonía de la elección, buscan ocultar la circunstancia de que todas las decisiones dependen en último análisis de nuestras proprias actitudes." (in Sobre el derecho y la justicia, Buenos Aires, Editorial Universitaria de Buenos Aires, 1977, p. 292).

De outra parte, muito embora esta intenção, muitas vezes implícita no aplicador da lei, de "congelar o significado da regra" (na expressão de HART), pretendendo defluir sua aplicação da pura e simples dedução, ou seja, partindo exclusivamente dos princípios da lógica formal, não há como se afastar, em consonância com o entendimento da grande maioria dos doutrinadores, que as normas jurídicas, independente de sua técnica de elaboração e a despeito da existência de precedentes, ao serem aplicadas sempre conterão, em algum aspecto ou ponto, um dado de indeterminação, isto é, conterão uma "textura aberta" (cf. H. L. A. HART, EI concepto de derecho, Buenos Aires, Abeledo Perrot, 1968, p. 159), nos mesmos moldes do que ocorre com o discurso dos leigos, cujo sentido varia de significado em consonância com o contexto, o tempo, e o lugar, independente da terminologia utilizada.

Por tudo o que foi dito, se por um lado invocar um princípio geral do direito na aplicação da lei, indutivamente encontrado a partir do ca- 
so concreto, é sempre mais conveniente, mais cômodo, do que assumir o inteiro peso de uma decisão, a aplicação destes princípios importa, ao mesmo tempo e incontestavelmente na consagração, ainda que vaga, ampla, da arbitrariedade e da dominação impostos pela estrutura do poder político.

Neste passo, a teoria crítica do direito, na construção de LUIZ FERNANDO COELHO, a partir de sua tese fundamental de que "o direito existe, não para manter a ordem, mas para transformá-la, e que a ciência do direito existe, não para constatar uma ordem imanente, revelada nas instituições, mas para transformá-la" (in Lógica jurídica e interpretação das leis, p. 339), em oposição ao pensamento jurídico tradicional, no qual o direito está sempre vinculado à idéia de ordem e ao mito da realidade das instituições, propõe uma inovação, a introdução da noção de categoria.

A expressão "categoria", porém, foge do caráter retórico que teve nas noções de MARX e WEBER, que nada traduzia da realidade, muito embora dela se aproximasse (como a categoria das classes sociais e das relações de produção, que nada tinham a ver com o cotidiano), para ser inovada, numa noção assim traduzida: "A teoria crítica do direito coopta a noção de categoria como conceito básico que pretende refletir os aspectos gerais e essenciais da realidade, mas limitado às condições concretas de cada tempo e lugar, ou seja, funcionando no interior de sua formação social específica." (LUIZ FERNANDO COELHO, in Introdução à crítica do direito, p. 25).

Diante disto, rejeitadas as denominadas categorias formais (esquema de pensamento, correspondendo à categoria lógica 'a priori', no sentido kantiano), bem como as categorias reais (equivalente a estrutura, como essência eidética condicionante da realidade, pelo seu caráter afastado da experiência histórica), mantém-se as categorias críticas, por envolverem instrumento de compreensão de uma realidade histórica concreta, mas aplicadas em função de um objetivo transformador da sociedade, visando indicar uma estratégia pol ítica.

São consideradas categorias críticas, na atual fase de formulação da teoria crítica do direito, a sociedade, a ideologia e a alienação (cf. LUIZ FERNANDO COELHO, Introdução à crítica do direito, p. 26).

Em face destas categorias críticas, o estudo do direito será feito a partir da sociedade e da ideologia e não vice-versa consoante a construção inclusive das teorias sociológicas, e a alienação, que afasta o homem do conhecimento próprio e do de seu lugar na sociedade volta-se para este conhecimento, desmistificando a falsa liberdade, uma vez que o objetivo da aplicação do direito se volta para uma verdadeira liberdade, para uma sociedade de homens desalienados.

Procurando romper com determinados obstáculos epistemológicos e construir um direito voltado para o real (de vez que a teoria crítica do direito parte do pressuposto de que o problema ontológico do direito é ser falso, na medida em que seus propósitos estão relacionados com a ideologia de manutenção da ordem social como ela é) e para o futuro 
(visando a transformação da sociedade), esta teoria alija os princípios gerais do direito, pela sua incompatibilidade com sua construção, propondo, em síntese, com as categorias críticas: (a) um direito voltado para uma sociedade melhor, em tempo futuro; (b) do ponto de vista ideológico, uma sociedade baseada em valores reais e não em mitos, ao contrário do que prega a teoria jurídica tradicional; (c) afastar os homens da alienação, a partir de uma sociedade de homens efetivamente livres, pensando com suas próprias cabeças, vendo na liberdade um autêntico dever.

Assim sendo, identificam-se na teoria crítica do direito, segundo LUIZ FERNANDO COELHO, o homem e a sociedade: o jurídico é o social. Como tal é que o direito passa a ser uma forma de transformação da sociedade.

Do ponto de vista prático, essa teoria prospectiva justifica, v. g., que o juiz decida contra a lei, transformando o direito e, desta sorte, colaborando para o aperfeiçoamento da sociedade, atitude esta tomada em nome da aplicação das categorias críticas.

A pertinência e coerência das categorias críticas com esta nova ordem de idéias é inafastável.

Contudo, sendo a teoria crítica do direito uma teoria ideologicamente engajada, como não poderia deixar de ser, uma dúvida e uma preocupação são suscitadas:

A sociedade humana vive em permanente fase de construção. Diante disto, não é possível que um grupo social seja tomado como parâmetro, pela perfeição de sua condiçã̃o de vida e organização, ou que determinados valores, mesmo reais, sejam tidos como acabados e incontestes.

A partir daí, o julgador, ao aplicar o direito, mesmo agindo em total liberdade, não estará também comprometido ideologicamente ao invocar as categorias críticas, pretendendo, face à sua cosmovisão, ditar os rumos do futuro de acordo com seus valores pessoais, como tal questionáveis? 